\title{
The Realistic Predicament and Solutions of College Student Association Management
}

\author{
Xianghua Ren \\ Shandong Technology and Business University \\ Yantai, Shandong, 264005
}

\begin{abstract}
There are some outstanding problems in the management of college student associations. Aiming at the problem, this paper puts forward the optimization measures such as " one heart and two rings" “ group learning organization pattern, relying on "The second class transcript" to enhance the vigor of the community development, strengthening the standard construction of the community, helping the ideological and political education work and so on. The measures will focus on making student associations play a greater role in advancing the construction of campus culture, strengthening the guidance of university students, and providing growth services.
\end{abstract}

Keywords-College student association, Management, Realistic predicament, Solution

\section{INTRODUCTION}

College student association is an important position for college students to "self-education, self-management, selfservice, self-supervision", and it is also an important carrier and extension arm for the Communist Youth League to realize the function of ideological guidance and growth service. In recent years, the management of college students ' associations has been paid more and more attention, and the organizational pattern of "one heart and two rings" is being constructed gradually, combing the problems existing in the management of student associations, which will help the management to be standardized and scientific, and make it become the active practitioner of socialist core values and the effective collaborator of ideological and political education of college students.

\section{Problems in the Management of College Students '} ASSOCIATIONS

\section{A. The organizational structure of the "one heart and two rings" regiment has not yet been fully established}

The Party committee of colleges and universities should give unified leadership to the work of student associations in our university. It is necessary to strengthen and improve the work of student associations as an important part of carrying out the educational policy of the Party and promoting quality education, which should be included in the overall work of colleges and universities. On the other hand, the number of student associations in colleges and universities is numerous. At present, under the background that the management of the association gradually moves towards the formality, the direct leadership of the college party committee to the student association has not been put into practice. The party committees of most colleges and universities have not yet made overall plans for student associations in terms of people, finances and materials, nor have they included in the budget, let alone policy support, especially in the absence of a system of regular support. The party committees of universities still have a long way to go for the leadership of the associations.

Associations as the students' "four selves" arm, extension effect is not ideal. We should consolidate and improve the organizational structure of "one heart and two rings" which is under the leadership of the Party. The student union organization is a main student organization under the leadership of the party and under the guidance of the group, so student union organizations at all levels should cooperate with the league to strengthen the guidance, management and service of student associations. In the specific work scenario, the relationship between student union and student association is still relatively independent, and the effect of student union on the guidance of student association and other organizations is limited. The phenomenon of "entertainment" in the activities of student associations is more serious, and the function of "selfeducation, self-management, self-service and self-supervision" has not been well brought into play. In addition, in some colleges and universities, there is a competition and opposition relationship between student unions and student associations. There are even problems such as the seizure of manpower, material resources, and honorary resources. It is precisely because the work patterns of the two organizations are not clarified. There is still a certain distance between the two relations and the organizational pattern of "one heart and two rings".

\section{B. Insufficient association development}

The formation of student association in colleges and universities was full of momentum and demonstrated the vitality of college student organizations. However, with the continuous development of community activities and organizations, organizational development shows a lack of succession. Many student associations in colleges and universities are in a state of taking the will of the management department as their own will, lacking independent thinking and independent behavior ability, resulting in unclear goals of organizational development, and lack of planning and goal guidance for long-term development, so that in the process of development, the organization has created a situation of "One session is full of vitality, two sessions are basically out of play”. 
The deviation of cognition to the status of college students' association directly leads to the deviation of the management attitude of the university student association management department to the university student association. At times, the management department of university students does not know the status and function of college student associations, and even considers them to be a kind of "burden". It is under the urge of this kind of thinking that a seemingly contradictory management strategy of " both managing death and being active" appears. Behind the management of marginalization is the marginalization of college students' community consciousness, which embodies and represents the marginalization of community status. The teachers' mobility also makes standardization and institutionalized management face great difficulties and challenges.

\section{The existence of irregularities in the management of the association}

Overall, student associations lack formal rules and regulations, although some associations have rules and regulations, and in the process of implementation, they gradually become mere formality. The management of college students ' associations is arbitrary. The politicization and operation of the student associations in colleges cause the decline or even loss of autonomy which belong to their own characteristics, resulting in the alienation of the club's autonomy. The college student association has the very big randomness characteristic in the management, on the one hand, the mobility of the teachers in the college students ' association is very large, the communication between the students and the teachers is only embodied in a certain activity, and the students are lack of long-term sustainable training. These results in the random and irregular development of college students' community activities and the role of the community organization as a growth platform are difficult to be fully reflected. On the other hand, college student associations lack institutionalized and standardized operating mechanisms and management systems, and the incentive, restraint, and competition mechanisms of community organizations are not perfect.

\section{Inadequate functioning of associations}

First, the role of ideological and political support is not good. The students' associations under the guidance of the League Committee of the colleges carry out ideological and political work with characteristics of diverse methods, extensive channels, and flexible operations. However, in the practical work, many colleges and universities often separate the two, and pay attention to the ideological and political theory of the first classroom education role, ignoring the role of the second class of college student associations. Second, the driving force of social practice is insufficient. College student association is an important carrier to promote students' participation in social practice and provides an important platform for students to participate in social practice. However, the strength and validity of college student associations in promoting the social practice of college students are very limited, the university student associations cannot give full play to the role of propaganda, organization and guidance of students to participate in social practice. This results in the blindness of students' individual participation in social practice activities, which directly affects the validity of student participation in social practice. Third, the effect of cultivating innovative spirit is poor. As an important supplement of the first classroom education, community activities are an important form and an effective supplement to achieve quality education, and play an important role in cultivating students' innovative spirit. However, in practice, the activities organized by the associations are still dominated by traditional activities. Even some of the activities focus on forms and light content, emphasize propaganda and light processes, emulate and lightly innovate. Because of the lack of innovation consciousness, limited activity funds, lack of funds and environment to carry out innovative activities, there is no incentive mechanism for innovative activities, which leads to the poor innovation of college community activities.

\section{Optimal Path}

\section{A. Construct the organizational pattern of "one heart and two rings" and strengthen the party committee's leadership to the association}

"The Implementation Plan for the Reform of the Communist Youth League in Colleges and Universities" clearly puts forward the construction of the "one heart and two rings" group learning organization pattern under the leadership of the Party. Under the leadership of the Party committees of colleges and universities, the Youth League Committee is the core and pivot, and the student union organization is the main organization of "self-service, self-management, self-education, and self-supervision". Taking student associations and related student organizations as the outer extension arm of the "four self" is an important measure to define the orientation and function of the community under the new situation, and is also the primary measure to strengthen the management of the community. The leaders of the Party committees of colleges and universities attach great importance to the construction of student associations in colleges and universities and regard it as an important carrier of deepening practical education in colleges and universities. They also put them in a very prominent working position, which is a crucial factor in doing a good job in the work of student associations in colleges and universities. The Party committees of colleges and universities unify the work of university students, they should regard strengthening and improving the work of student associations as the educational policy of the Party, bring the important part of promoting the comprehensive reform of higher education into the whole work of colleges and universities, integrate the development of the community into the talent training plan of the school, embed the credit system of "second classroom transcript", and formulate the support and guarantee system of the college student association which is suitable for the training mode of the university's talents. Party committees in colleges and universities must pay attention to the professional development level of student community activities, attach importance to the appointment of professional teachers as community instructors, and let specialization become the basis for the promotion of connotation, standardized management, and characteristic development of associations. It is necessary 
to plan and design the development level of the student association from the angle of reflecting the development level of the university, and to build the first-class student association as the construction of the first-class university and the firstclass subject. According to the organization pattern of "one mind and two rings" under the leadership of the Party committee, the school Communist Youth League organization should give full play to the core leading role. According to the school's characteristics of educating people, we will perform the main management functions of our student's associations and formulate the development plan for college students' association. We shall comprehensively incorporate the management and development of university associations into the core category of the core educating business of the Communist Youth League's "second classroom transcript". Make college students' communities become an important physical platform for the cultivation of school talents. The Student Union must focus on the construction of the organizational pattern of "one heart and two rings" and strictly implement the guidance, management, and service functions for college student associations.

\section{B. Relying on the overall implementation of the "second class transcript" system to enhance the vitality of community development}

The "second class transcript" system is a leading project to deepen the reform of the Communist Youth League in colleges and universities and is an important measure for the reform of the Communist Youth League in colleges and universities in response to the education system and mechanism. The second classroom is an important platform for educating people outside the first classroom. It is an important position for college students to strengthen ideological and political education and develop cultural quality education and it is also an important area for the Communist Youth League to serve the school education center and the basic tasks of enhancing morality and fostering talents. College student associations are important platforms for students' knowledge practice, skills development, and quality development. They must use the "second class transcript" to promote community development. The key to the implementation of the system of "second class transcript" lies in the content supply of the project activity curriculum and the standardization of the second classroom in the credit system mode, which has the inherent logic unity with the strengthening of the standardization and specialization management of college students ' association. The curriculum development and design of all project activities of college student associations should be carried out according to the requirements of the curriculum design of "second class transcript", and the contents of community activities should be fully integrated into the category of "second class transcript" system. In this way, both the standardization and specialization of the activities of the community are improved, and the supply of the content of the "second class transcript" is enriched, which can realize the coordination and interaction of the two.

\section{Implement the "Interim Measures for the Administration of College Students' Associations" and strengthen the standardized construction of associations}

"Interim Measures for the Administration of College Students' Associations” is of great significance for deepening the implementation of "Opinions on Further Strengthening and Improving College Propaganda and Ideological Work in the New Situation" and "Opinions of the Central Committee of the Communist Party of China on Strengthening and Improving the Party's Group Work", further standardizing the management of college student organizations, deepening the educational function of college student organizations, and actively promoting the healthy development of college student organizations, which is a guide to the development of college student associations and must be strictly implemented. The successful experience of college student associations lies in the requirements of self-management of students in the university management system, the development of the community is consistent with the goals of education, the complete rules and regulations provide a good external environment for the development of the community, strict examination and approval and year-end assessment and also the mechanism played a supervisory role in the development of the community. The management of university student associations should be based on national policies, the development of universities, and the needs of students, and should establish a perfect management framework for student associations. The standardized management program can inspire the enthusiasm of college students to participate in community activities, and is also a solid foundation for the development of associations. It also ensures that the management of associations is scientific and standardized so as to form a strong execution force and avoid management errors to make blindness and randomness in the development of the community due to human factors. Therefore, in accordance with the requirements of the "Interim Measures for the Administration of College Students' Associations", a detailed implementation schedule and a standardized community management system shall be established, which will not only help strengthen the selfconstruction of student organizations, but also increase the enthusiasm of the members of the association.

\section{Implementing the spirit of ideological and political work conferences in universities and giving full play to their role in revitalizing campus culture and improving students' comprehensive quality}

In accordance with the spirit of the National Conference on Ideological and Political Work in Colleges and Universities and the "Outline for Enhancing the Quality of Ideological and Political Work in Colleges and Universities", in order to do a good job of ideological and political work in colleges and universities, it is necessary to carry forward the spirit of reform and innovation make the ideological and political work be grounded and enter the hearts of people, and play an active role in the Communist Youth League, Student union organizations and student associations. It is necessary to further grasp the categories and characteristics of college student associations and actively explore new ways and new ways for the construction and development of all types of associations. 
Focusing on cultivating featured culture, guiding the associations to focus on innovations in cultural concepts, supplemented by institutional innovations and carrier innovations, launching featured activities that are in line with the categories of clubs and in line with the needs of members, encouraging individual development, innovation and development, highlighting the fashion of various types of club culture Sexuality and advanced nature, and strive to form a unique type of attractiveness and brand influence. We should combine ideological and political work with the characteristics of community organizations, combine with cultural guidance, combine with the functions of the mass organizations, combine with practical difficulties, integrate with new media, combine with students' growth goals, and work hard to create a new situation in the Communist Youth League that uses ideological and political work as a means to promote the development of associations and use association as a frontline to harvest the results of ideological and political work, so as to enhance the appeal of the association and the effectiveness of education.

\section{CONCLUSION}

The university student association is a mass organization which is composed voluntarily by the university students according to the common interest hobby and carries out activities according to the constitution. It is an important channel to enrich the campus cultural life, is an important position for college students to realize "self-education, selfmanagement, self-service and self-supervision”, and is also an important carrier and extension arm of Youth league to organize youth, guide youth, serve youth, safeguard young people's lawful rights and realize the function of thought leading and growing service which is of great significance for strengthening the management of college students ' associations.

\section{REFERENCES}

[1] The Central Committee of the Communist Party of China, Opin ions on strengthening and improving the work of the Party and League [Z], 2015.2.3.

[2] The Communist Youth League Central Committee, the Ministry of Education, and the National Association of Students, Interim measures for the management of college student associations [Z], 2016.1.12.

[3] Chinese Communist Party Department of Education, Implementation outline of the quality improvement Project of ideological and political work in colleges and universities [Z], 2017.12.4.

[4] The Communist Youth League Central Committee and the Ministry of Education, Implementation scheme of the reform of the communist youth league in colleges and universities[Z], 2016.11

[5] Yang Fan, etc. The Optimized approach to the educational function of college student associations [Z], Research in Higher Education, 2016, (12). 